\title{
ESTUDOS SOBRE A QUESTÃO DO FUNDAMENTO EM HEIDEGGER
}

\author{
Studies on the question of the foundation in Heidegger
}

Bartolomeu Leite da Silva

UFPB

\begin{abstract}
Resumo: Este artigo aborda alguns aspectos fenomenológicos da questão do fundamento com relação ao conceito de mundo na obra a Essência do Fundamento, de Heidegger. O conceito fenomenológico de mundo, nos termos em que Heidegger irá abordar, tem suas raízes em Kant, e consistia em ser um resultado puro produzido pelo pensamento. Heidegger apresentará uma concepção fenomenológica completamente nova do mundo numa relação direta com o homem enquanto Dasein. Com isto, Heidegger atesta que homem e mundo partilham da mesma base quanto ao princípio de existência, e apresenta um novo fundamento do homem ligado a um contexto completamente antropológicoexistencial.
\end{abstract}

Palavras-chave: Mundo, antropologia, Dasein

Abstract: This article aims to approach the phenomenological view on the essence of reason inside the boundaries of Heidegger's work The essence of ground. The world as concept was firstly conceived by Kant's philosophy, which showed a conception of world as an objectiveness produced by the reason. Following this way, Heidegger will elaborate an all new phenomenological conception of the world together the conception of man, as a Dasein. From this Heidegger's conception of man, is proposed that man and world are based on the same existence of the Dasein, as a new grounding and showing a new philosophical anthropology. Man and world, hereafter, must be correlate in its phenomenological existence.

Keywords: World, anthropology, Dasein.

\section{Delimitação da questão}

A expressão "mundo como problema" pertence a Heidegger. Ela não designa, a princípio, nada de caráter psicológico, existencial ou fatídico na relação do ente com o mundo, mas preliminarmente limita os horizontes da questão de mundo, ou simplesmente, exibe os caminhos da questão. Heidegger prende a questão de mundo, em sua origem, ao homem, na condição de ente (Dasein) humano, como referencial da 
existência do mundo. A questão de mundo, por outro lado, não se limita ao homem, dada sua complexidade e sua natureza. Tampouco ela se pauta na ideia de uma antropologia salvífica, como forma de evitar uma derrocada e uma queda (Fall). A ideia de uma certa antropologia de caráter fenomenológico-existencial bem poderia daí ser extraída, mas esse não representa o principal desejo de Heidegger.

Mundo e homem constituem um binômio fundamental para a elucidação do problema do mundo, mas não constituem, por outro lado, os limites da questão. Esse binômio indica apenas os passos que a questão de mundo deve percorrer. Mundo e homem são elementos prévios e constitutivos do acontecer do mundo, pontos de partida e de chegada, constitutivos de um destino existencial do homem. Mundo e homem constituem pressupostos inevitáveis e elementos primordiais para a abordagem metafísica da questão de mundo. Eles constituem as instâncias objetiváveis, mas não objetivas, da questão. Eles não são simplesmente eleitos entre outros. Desse modo, há que tomá-los insistentemente para, com eles e através deles, ultrapassar os limites do mundo objetivo, e chegar ao campo inevitável da compreensão (Vestehen), lugar onde o mundo se desvela ao ser em seu ser. O desvelamento do ser se dá através do movimento da ultrapassagem. Ultrapassagem (Überstieg) é o termo-chave que Heidegger usa para designar o caráter de transcendência do homem em relação ao mundo. Enquanto transcendente, o homem dirige-se ao mundo, e neste movimento de transcendência se dá a existência.

\section{A posição histórica da questão}

Heidegger trabalha a questão de mundo de duas maneiras:

A primeira delas é a via ontológica, na qual ele tenta recuperar o sentido e a importância do mundo para o debate das questões humanas em geral. Uma abordagem nestes termos permanecia encoberta desde muito tempo pela tradição, uma espécie de "sono dogmático", do qual Heidegger tenta acordar. Essa questão é transparente nas obras do autor, e está, em geral, subentendida no tema da "desconstrução".

A segunda delas é a via metodológica, na qual o tema do mundo é abordado de forma objetiva e programática. São três os passos básicos do autor. 
1. Na obra A Essência do Fundamento é apresentada uma visão historiográfica da questão. Nesta obra, Heidegger trabalha os conceitos históricos de verdade, fundamento e mundo, vistos retrospectivamente a partir da metafísica fundamental. Heidegger parte do conceito leibniziano de principium rationes, quando historicamente se faz a distinção entre verdade e fundamento, chegando a Kant, onde se deslinda o cerne da questão: mundo como propriedade existentiva da razão, mundo como produto do entendimento humano, mundo como transcendência.

2. Na obra Ser e Tempo é apresentada uma visão fenomenológica da questão mundo e homem, mas ainda não se alcançam todos os objetivos de uma antropologia pragmática: "conhecimento do mundo é sinônimo de uma antropologia pragmática (ciência do homem)"

3. É, porém, na obra Conceitos fundamentais da metafísica: mundo, finitude e solidão que é apresentada uma visão que funda a ideia de uma metafísica fundamental, a partir da fenomenologia, qual seja, a que apresenta uma visão do homem e do mundo a partir de um exame comparativo e de uma análise fenomenológica, capaz de elucidar questões fundamentais do conceito de mundo e de homem, simultaneamente.

O exame comparativo se dá a partir da tese inicial: "o homem tem (o) mundo", que se elucida, por sua vez, nas seguintes três teses: “1. A pedra é sem mundo, 2. 0 animal é pobre em mundo; 3 . O homem é formador de mundo".

Tratando do programa heideggeriano da exposição da questão de mundo, Stein afirma que,

na sua investigação do conceito de "mundo", Heidegger explora três caminhos: 1) a análise ontológico-compreensiva (In: Ser e Tempo); a análise da gênese histórico-filosófica (In: Sobre a essência do fundamento); 3) a análise comparativo-diferencial: mundo da pedra, mundo do animal e mundo do homem; homem: sem mundo, pobre em mundo e formador de mundo (Conceitos fundamentais da metafísica: mundo, finitude, solidão).

Nosso objetivo é fazer uma leitura do movimento heideggeriano de desconstrução do conceito de mundo, não necessariamente seguindo os passos metodológicos da exposição do autor. 


\subsection{Os modos de se pôr a questão}

A questão de fundo, em relação ao conceito de mundo que aqui perseguimos, está colocada, em linhas gerais, em "A caminho de uma fundamentação pós-metafísica", de E. Stein, num capítulo intitulado "As origens do conceito de mundo em Heidegger", cuja tese principal consiste em afirmar que Heidegger interpõe dois sentidos ao conceito de mundo:

no primeiro sentido ele apresenta o mundo enquanto continente, totalidade; no segundo sentido, quanto ao homem, Heidegger subdivide este conceito em duas partes: o homem mundano, habitante do mundo; e o homem divino, temente a Deus. Portanto, é na cosmologia, na história deste conceito desde os gregos, que Heidegger busca seu conceito de mundo ${ }^{1}$.

Ou seja, trata-se mesmo, para Heidegger, de um conceito plenamente antropológico de mundo. Essa leitura é feita partindo de uma fundamentação possível da teoria do conhecimento, com o fim de relacioná-la com os fundamentos do conceito de pragmática comunicativa dos sujeitos, conceito forte nas teorias ético-discursivas de Apel e Habermas. Para nós, a pragmática comunicativa assenta seu peso na compreensão de mundo como "lugar por excelência do entendimento mútuo entre os sujeitos comunicativos", ideia subjacente à compreensão heidegeriana de ser-nomundo (In-der-Welt-sein). O ser que se afirma nos parâmetros de um ser no mundo só pode carregar o caráter de ser-com os outros. Donde se chega à ideia de uma comunidade de comunicação.

\section{Leibniz e o princípio de razão suficiente}

O problema do fundamento é tratado, na tradição metafísica, apoiado na ideia de razão como "razão suficiente", e, como tal, "princípio supremo" de todas as coisas. Esta afirmação pressupõe a tese geral seguinte: nihil est sine ratione, nada existe sem razão. O que esta tese enuncia é o "princípio de uma razão suficiente" sempre presente nas coisas de um modo geral e a qualquer tempo, onipresente. O princípio da razão

1 STEIN, E. A caminho de uma fundamentação pós-metafísica. p. 101. See too HEIDEGGER. M. A essência do fundamento. pp. 43ss. 
suficiente esconde em si o problema capital do conhecimento humano, qual seja, o de só considerar a pergunta pelo fundamento extrinsecamente, e com isso ofuscar a verdadeira face da questão, ao confundir verdade e fundamento. A versão positiva do princípio da razão suficiente diz: omne ens habet rationem, todo ente tem uma razão, evidenciando, assim, uma relação direta com os entes em geral.

Porém, se a razão também é um ente, eis a questão que resta responder nesta proposição. Deste modo, o princípio da razão suficiente se apresenta como princípio não-problemático, para o qual não é preciso questionamento algum:

a proposição enuncia algo sobre o ente em referência a algo como <razão>. No entanto, não se especifica nesta proposição o que constitui a essência da razão. Isso é pressuposto para esta proposição como "representação" óbvia.

Duas coisas devem ser observadas nesse princípio. (1) o modo como ele se põe, e (2) o modo como ele põe as coisas. [isso constitui, obviamente, os modos possíveis da relação do princípio consigo mesmo e com as coisas]. Para Heidegger, ambos modos permanecem problemáticos, dado que o problema central do fundamento permanece ignorado: “... tanto no modo de se pôr quanto também ao "conteúdo" por ele posto, o "princípio" da razão é problemático".

\section{Verdade predicativa (proposicional) e verdade prepredicativa (ôntica)}

Na seqüência da exposição, Heidegger toma o comentário de Leibniz ao principium rationis. Heidegger vê, nesses comentários, que se evidencia uma distinção entre a questão da verdade e a questão do fundamento. Verdade é a conseqüência de uma enunciação de proposições. Ela é a incursão do predicado $\langle\mathrm{P}\rangle$ no sujeito $\langle\mathrm{S}\rangle$, ou mesmo uma conexão necessária entre sujeito e predicado: "a essência da verdade, porém, reside na connexio (symploké) de sujeito e predicado". Nesta argumentação (aqui resumida) de Leibniz, não há muito que se discutir, dado que a relação da verdade com os entes afirmados é mostrada sem muito relutância na conexão entre sujeito e predicado. Porém, quanto à questão do fundamento fica por explicitar, pois, por trás desta verdade inerente às proposições (verdade proposicional) há que se pressupor um 
ente real que a fundamente, uma verdade mais originária, ou verdade ôntica, como chama Heidegger. Assim, "verdade proposicional está radicada numa verdade mais originária (desocultamento), na revelabilidade prepredicativa do ente, a que chamamos verdade ôntica" (Heidegger, 1988, p.21).

A verdade predicativa, no entanto, torna-se importante no processo de desocultamento do ser, e, antes, na revelabilidade do ente, na medida em que nela se enuncia a verdade de um ente (conexão da representação). A verdade predicativa é uma verdade que fala sobre o ente. Porém ela ainda não constitui uma explicitação total do ente. Ela indica apenas um nível da questão. Heidegger eleva essa questão ao nível das regiões do ente, que são os vários níveis em que o ente pode se dar a conhecer:

A caracterização da verdade prepredicativa como intuir de bom grado se insinua porque a verdade ôntica, e presumivelmente genuína, se determina antes de mais nada como verdade proposicional, isto é, como <conexão da representação>

“Conexão da representação" é o estado que a verdade prepredicativa assume ao se revelar ao ente, quando ela assume uma função predicativa, exibindo a verdade proposicional como verdade ôntica. Como suporte à verdade ôntica, Heidegger fala num acontecer simples, que se esconde por trás dos atos proposicionais, um mero representar, isento de toda conexão, um acontecer originário, cuja função é a objetivação do ente, já sempre necessariamente revelado.

O movimento que se mostra neste <já sempre revelado> manifesta a constituição do ser do ente, ser-quê e ser-como (Was- $u$. Wie-sein): só o desvelamento do ser possibilita a revelabilidade do ente. Este desvelamento, como verdade sobre o ser, chama-se verdade ontológica.

Verdade ontológica e verdade ôntica são os conceitos fundamentais com que Heidegger introduz a sua teoria sobre o ser. As duas se relacionam na medida em que o ente só se revela guiado e iluminado por uma compreensão do ser: "a verdade ôntica e ontológica referem-se, de modo diverso respectivamente, ao ente no seu ser e ao ser do ente". Portanto, a verdade ontológica é condição necessária para a revelação do ser do ente, e o ente, por sua vez, é a condição de revelabilidade do ser. Isto não constitui 
um círculo vicioso, mas um círculo ontológico dentro do qual o ser se mostra ao ente. Porém, interpelar o ente na condição de algo (etwas als etwas) não significa ainda desvelar o ser em sua revelabilidade possível, dado que o movimento fenomenológico da revelação é constante, porém acessível em seus diversos momentos:

interpelar algo enquanto algo não significa necessariamente ainda apreender na sua essência o que assim é interpelado. A compreensão do ser (logos num significado muito amplo), que antecipadamente ilumina e guia todo o comportamento para com o ente, não é nem uma captação do ser como tal, nem sequer uma apreensão do que assim é captado (logos no significado mais restrito $=$ conceito $<$ ontológico $>$ ) .

Ao problematizar o princípio da razão suficiente, Heidegger afirma que não se deve confundir o problema da verdade com o problema do fundamento, fato que perdurou durante séculos na tradição da filosofia. Segundo Heidegger, devemos distinguir entre verdade proposicional, ou verdade predicativa, obtida pelo são raciocínio, nos termos de uma conexão real do pensamento com o objeto, e uma verdade prepredicativa, ou pré-ontológica, inferida nos termos de que qualquer predicação só se torna possível pelo ente revelador do ser, e que ainda o ente revelador do ser revela assim seu ser: "chamamos, pois, à compreensão do ser, que ainda não chegou ao conceito, a compreensão pré-ontológica ou também ontológica, em sentido mais lato".

Deste modo, podemos falar de fundamento diversamente de verdade, em tom inclusivo mais do que exclusivo. Fundamento é aquilo que de mais originário se dá na revelabilidade do ser, portanto, algo anterior. Esta anterioridade é algo que está sempre disponível, possibilitando ao ser revelar-se ao e através do ente. Entre os dois estágios de revelação do ser, o momento do ente e o momento do ser, ou verdade e fundamento, habita o que Heidegger chama de diferença ontológica. A diferença ontológica estabelece os limites de compreensão do ente em relação ao ser e os limites de revelabilidade do ser em relação ao ente. Este movimento pode ser caracterizado, segundo Heidegger, como um movimento de transcendência do ser para seu ato de revelação, e nessa transcendência reside exatamente o problema do fundamento. Portanto, 
Se ... a essência do fundamento tem uma relação interna com o problema da verdade, então também o problema do fundamento só pode residir onde a essência da verdade obtém a sua possibilidade interna, na essência da transcendência. A questão da essência do fundamento torna-se o problema da transcendência.

\section{O movimento da transcendência e a posição do mundo}

Transcendência é o termo que Heidegger usa para caracterizar o movimento do ser em relação ao mundo. Trata-se do termo médio entre o ente e o ser, o que se poderia chamar diferença ontológica. Diferença ontológica significa que o ser se revela através do ente, e o ente só carrega essa possibilidade de revelação do ser segundo a disponibilidade do próprio ser. Entre os dois há o que Heidegger chama de diferença ontológica:

transcendência significa ultrapassagem. Transcendente (o que transcende) é o que realiza a ultrapassagem, persiste na ação de ultrapassar. Enquanto acontecer, o ultrapassar é próprio de um ente. Formalmente, a ultrapassagem pode conceber-se como uma <relação $>$ que se estende < de > algo <para > algo.

A transcendência, enquanto ultrapassagem, implica num movimento entre dois pontos, de <algo> para <algo>. Quem ultrapassa e o que se ultrapassa nesse movimento, eis a questão que se impõe. Ultrapassar é o característico movimento do ente. $\mathrm{O}$ sujeito ativo da ultrapassagem é o próprio ente, assim como ele próprio é quem é ultrapassado. Como pode isso? Não cai este movimento da ultrapassagem sobre um ponto sem saída, uma contradição real?

Para se evitar este tipo de acusação, Heidegger mostra que o movimento da transcendência não é uma propriedade do ente, no sentido em que ele possui a capacidade de transcender para algo, mas transcendência e ente transcendente existem num só movimento. Eles são co-existentes. Desse modo, é próprio da transcendência acontecer pelo ente, e é igualmente próprio do ente acontecer pela transcendência. Não poderíamos pensar em algum ente que optasse, talvez, por não transcender, supondo 
que houvesse objetos em um nível em que ele não quisesse ali penetrar. A transcendência é própria do ente.

O fato de o ente mesmo ser ultrapassado não significa um vôo para fora de si mesmo, nos termos de uma filosofia moderna do sujeito (Kant), mas significa um ato de revelação do ser do ente que é ele próprio. $O$ ato de revelação, no entanto, só é possível porque desde sempre o ser existe e, imperativamente, faz esse movimento acontecer. Segundo Heidegger,

o sujeito nunca existe antes como <sujeito> para, em seguida, no caso de haver objetos presentes à mão, também transcender, mas, ser-sujeito significa: ser ente na e como transcendência.

\section{Mundo e transcendência: o movimento da ultrapassagem}

A ultrapassagem acontece dentro de um espaço onde o ente revela sempre o ser. A esse espaço podemos chamar mundo. Mundo, aqui, ainda se caracteriza de forma preliminar, para Heidegger, mas, sobretudo, carrega as feições de um mundo humano, lugar em que o ente está simplesmente aí (Dasein):

a transcendência, na significação terminológica que importa clarificar e apresentar, significa o que é próprio do estar-aí humano e, decerto, não como um modo de comportamento entre outros possíveis, ocasionalmente posto em execução, mas como constituição fundamental deste ente antes de todo comportamento.

É o inevitável movimento da ultrapassagem que dá ao ente a sua possibilidade de existência. "Aquele que não ultrapassa não existe" é um tipo de pensamento fraco, inconseqüente. Por outro lado, aquele que ultrapassa existe é um tipo de pensamento tautológico, pois existir significa ultrapassar. A ultrapassagem, dada no movimento da transcendência, é aquilo que possibilita a existência em geral. Portanto, ela é natural do ente, e constitui o movimento da revelação do ser. Existência significa o encontro do sujeito com o mundo, o lugar para onde ele transcende, e lugar onde ele encontra a si mesmo. A referência a si mesmo (Selbst) evocada por Heidegger constitui uma espécie de recusa a um certo psicologismo, bem como ao binômio essência-existência que marcou a tradição metafísica. Tratava-se, para esta, de saber quem existia antes. Uma 
espécie de essência do sujeito, ou um sujeito em si não é mais possível de se entender na metafísica fundamental inaugurada por Heidegger. Sujeito, doravante, só existe no e com o mundo. Desde sempre, para Heidegger, sujeito e mundo são elementos indissociáveis no plano da existência e do conhecimento.

\section{Transcendência como ser-no-mundo}

No movimento da ultrapassagem, o ente assume a condição de estar aí, ser jogado na existência. Com isso, o movimento da ultrapassagem se torna total e efetivo, não acontecendo em momentos volitivos do sujeito, simplesmente acontece. No movimento da ultrapassagem, o objetivo do sujeito não é encontrar-se a si mesmo, dado que seria um movimento desnecessário. Ele transcende a si próprio, mas não para chegar a si próprio. Afinal, em direção a quê se dirige o sujeito na ultrapassagem? A isso responde Heidegger:

Aquilo em direção ao qual o estar-aí como tal transcende damos o nome de mundo e definimos agora a transcendência como ser-no-mundo. O mundo constitui a estrutura unitária da transcendência; enquanto pertencente a tal estrutura, o conceito de mundo chama-se transcendental.

Todo o movimento do transcendental, portanto, do mundo, acontece com vistas a uma existência radical do ser. Ou seja, o mundo existe para o ser e vice-versa, transcendência e imanência reduzem-se à existência, ao mundo, ao transcendental. Kant cunhou o transcendental com um sentido diverso do de Heidegger, embora já apontasse para uma relação entre os entes e o mundo de modo ontológico. Transcendental, com o sentido crítico que Kant lhe atribui, tem a ver com a condição de possibilidade de existência das coisas. Todo o conhecimento do ser, portanto, o universal, torna-se o transcendental para a Kant.

Certamente esta interpretação aponta para tudo que Heidegger inaugura, mas ainda restringe-se aos modos sensitivos da realidade. O termo, em Heidegger, é totalmente ambicioso. Transcendental é o ser-no-mundo, no mesmo grau em que o serno-mundo é a transcendência. Já o ser-no-mundo significa a presença constante, ou a existência, de um estado-de-coisas (Fall), um estar-aí jogado na existência. Mundo não 
é uma propriedade do sujeito. Esta seria uma interpretação pré-filosófica, vulgar. Mundo é reunião <total> das coisas. Ele se deixa entender pelo movimento constante da transcendência, onde tudo existe. Concluindo, transcendência significa então:

estar integrado no resto dos entes já sempre presentes, respectivamente, no meio dos entes que se podem multiplicar continuamente até ao ilimitado. Mundo é então o termo para tudo o que é, a totalidade, como a unidade que determina o <tudo> como uma reunião, e não mais além.

\section{Mundo e ser-no-mundo}

Cabe agora relacionar mundo, ser-no-mundo e estar-aí. Mundo já pode ser compreendido como reunião de tudo o que é. Devemos, agora, a partir desta compreensão, estabelecer relações entre o estar-aí humano, como constituição ontológica essencial, e ser-no-mundo, condição fundamental que o estar-aí humano traz consigo. Segundo Heidegger, atribuir ao estar-aí o ser-no-mundo como constituição fundamental significa enunciar algo sobre a sua essência (a sua mais peculiar possibilidade interna enquanto estar-aí).

Ao estar-aí não se pode atribuir a transcendência como característica fundamental, dado que transcendente é tudo o que "pertence ao resto do ente". O estar-aí humano já carrega consigo desde sempre a condição, e não possibilidade, de ser-no-mundo. Ser-no-mundo não pode ser um atributo, mas um constitutivo essencial. Conclui Heidegger, então, que a proposição "o ser-no-mundo pertence à essência do estar-aí humano" ${ }^{2}$ é evidentemente falsa, dado que outros modos de existência nãofática são tomados como possibilidades reais.

Falar do estar-aí humano como ser-no-mundo significa enunciar algo de sua constituição fundamental. Portanto, ser-no-mundo e estar-aí humano representam modos de ser do ente que revela o ser. E essa junção faz do ente humano um ente especial. Por conseguinte,

o estar-aí não é ser-no-mundo porque e somente porque existe faticamente, mas, pelo contrário, pode apenas ser como existente, isto é, como estar-aí, porque a sua constituição essencial reside no ser-no-mundo.

2 HEIDEGGER. M. A essência do fundamento. p.41 
Com relação ao ser-no-mundo como constituição fundamental do estar-aí humano, Heidegger enumera três teses possíveis que podem ser ditas em relação a essa tese central: (1) “o estar-aí fático está num mundo (presente no meio de outros entes); (2) "é inerente à essência do estar-aí que ele esteja no mundo (que ele esteja necessariamente <ao lado> de outros entes); e (3) "da essência do estar-aí enquanto tal faz parte o ser-no-mundo".

Em relação à tese (1): esta tese se revela uma tautologia e nada acrescenta para uma real compreensão do problema do estar-aí humano. Ser é ser-no-mundo, portanto, a faticidade não pode ser uma possibilidade, mas faz parte da constituição fundamental do estar-aí.

Em relação à tese (2): esta tese se revela falsa na medida em que o estar-aí só pode ser afirmado no e com o mundo. Mundo comporta um caráter existencial fundamental em que o estar-aí se revela, simplesmente existe lá.

Em relação à tese (3): esta tese se revela a mais original e plausível, dado que nela se descerra o problema da transcendência. Ela revela o caráter do existir fático do estar-aí humano. Ela une os dois elementos (estar-ai e ser-no-mundo) a um terceiro, que é o próprio mundo, numa união tal que nenhum desses elementos pode existir separadamente. Mundo coroa a relação do ente que transcende e de tudo que the é transcendente, por isso, ele só pode ser na medida em que o estar-aí com ele e nele existe.

Essas três teses revelam a simplicidade com que o ser pode se desvelar, mas não podemos concluir ainda que o processo de desvelamento do ser seja simples neste mesmo grau. Com isto, Heidegger insinua os vários modos de ser em que o ser pode se dar (revelar-se) ao ente. Este caminho dos "modos de ser" é simplesmente abandonado aqui por nós.

\section{Referências bibliográficas}

HEIDEgGeR, M. El ser i el tiempo. Trad. De José Gaos. México: Fondo de cultura 
económica, 1997. Tít. Original: Sein und Zeit. Max Niemeyer Verlag, Halle, 1927.

HEIDEGGER, M. Les concepts fondamentaux de la métaphysique: monde-finitudesolitude. Trad. de Daniel Panis. Paris: Gallimard, 1992. Título original: Die Grundbegriefe der Metaphysik: Welt-Endlichkeit-Einsamkeit, Band 29/30 Gesamtausgabe.

HEIDEGGER. M. A essência do fundamento. Ed. bilbigüe. Trad. de Artur Morão. Lisboa: Edições 70, (1988). Tít. original: Vom Wessen des Grundes. [Tradução brasileira de Ernildo Stein: In: Heidegger e Sartre. Col. Os Pensadores, São Paulo:Abril Cultural, 1973].

STEIN, E. A caminho de uma fundamentação pós-metafísica. Porto Alegre: Edipucrs, 1997. 163p.

Doutor em Filosofia (PUCRS) Professor do PPG de Filosofia (UFPB)

E-mail: blsic@hotmail.com 